\title{
Complete genome sequence of Mesorhizobium australicum type strain (WSM2073')
}

\author{
Wayne Reeve ${ }^{* 1}$, Kemanthi Nandasena ${ }^{1}$, Ron Yates ${ }^{1,5}$, Ravi Tiwari ${ }^{1}$, Graham O'Hara ${ }^{1}$, \\ Mohamed Ninawi ${ }^{1}$, Wei Gu${ }^{2}$, Lynne Goodwin ${ }^{2}$, Chris Detter ${ }^{2}$, Roxanne Tapia ${ }^{2}$, Cliff Han², \\ Alex Copeland ${ }^{3}$, Konstantinos Liolios ${ }^{3}$, Amy Chen ${ }^{4}$, Victor Markowitz ${ }^{4}$, Amrita Pati ${ }^{3}$, \\ Konstantinos Mavromatis ${ }^{3}$, Tanja Woyke ${ }^{3}$, Nikos Kyrpides ${ }^{3}$, Natalia Ivanova ${ }^{3}$, \& John \\ Howieson ${ }^{1}$. \\ ${ }^{1}$ Centre for Rhizobium Studies, Murdoch University, Western Australia, Australia \\ ${ }^{2}$ Los Alamos National Laboratory, Bioscience Division, Los Alamos, New Mexico, USA \\ ${ }^{3}$ DOE Joint Genome Institute, Walnut Creek, California, USA \\ ${ }^{4}$ Biological Data Management and Technology Center, Lawrence Berkeley National \\ Laboratory, Berkeley, California, USA \\ ${ }^{5}$ Department of Agriculture and Food, Western Australia, Australia
}

Correspondence: Wayne Reeve (W.Reeve@murdoch.edu.au)

Keywords: root-nodule bacteria, nitrog en fixation, evolution, lateral transfer of genes, integ rative and conjug ative elements, symbiosis, Alphaproteobacteria

Mesorhizobium australicum strain WSM2073 was isolated from root nodules on the pasture legume Biserrula pelecinus growing in Australia in 2000. This aerobic, motile, gram negative, nonspore-forming rod is poorly effective in $\mathrm{N}_{2}$ fixation on $B$. pelecinus and has gained the ability to nodulate $B$. pelecinus following in situ lateral transfer of a symbiosis island from the original inoculant strain for this leg ume, Mesorhizobium ciceri bv. biserrulae WSM1271. We describe that the genome size of $M$. australicum strain WSM2073' is 6,200,534 bp encoding 6,013 proteincoding genes and 67 RNA-only encoding genes. This genome does not contain any plasmids but has a $455.7 \mathrm{~kb}$ genomic island from Mesorhizobium ciceri bv. biserrulae WSM1271 that has been integ rated into a phenylalanine-tRNA gene.

\section{Introduction}

Biological nitrogen fixation (BNF) contributes substantially to the productivity of sustainable agriculture around the world and approximately $80 \%$ of biologically fixed nitrogen $(\mathrm{N})$ is estimated to be contributed by the symbiotic association between root nodule bacteria (RNB) and leguminous plants [1]. This process of symbiotic nitrogen fixation (SNF) enables 175 million tons of atmospheric nitrogen $\left(\mathrm{N}_{2}\right)$ to be fixed each year into a plant available form. SNF therefore reduces the need to apply fertilizer to provide bioavailable nitrogen, decreases greenhouse gas emissions derived from fertilizer manufacture, alleviates chemical leaching into the environment from the over application of fertilizer, and substantially enhances soil nitrogen for crop and animal production [2-4]. Because of substantial SNF benefits, considerable effort has been devoted to sourcing legumes from different geographical locations to improve legume productivity in different agricultural settings [3].
The Mediterranean legume Biserrula pelecinus L. is one of only three deep rooted annual legume species widely used in commerce with the potential to reduce the development of dryland salinity in Australia and was therefore introduced into Australia in 1994. Native RNB in Australian soil were not capable of nodulating B. pelecinus and therefore this host was inoculated with the inoculant strain Mesorhizobium ciceri bv. biserrulae WSM1271 [5] to obtain an effective symbiosis. Six years after the introduction of this legume into Western Australia, isolates were recovered from root nodules on B. pelecinus growing in Northam, Western Australia that were compromised in their nitrogen fixation capacity. The gradual replacement of the inoculant by established strains of RNB that are competitive for nodulation but suboptimal in $\mathrm{N}_{2}$ fixation threatens the successful establishment of this new legume in agriculture [6]. 
One of these poorly effective but competitive strains that was isolated from a nodule of $B$. pelecinus grown in the wheat belt of Western Australia can only fix $<40 \% \mathrm{~N}_{2}$ compared to the original inoculant $M$. ciceri bv. biserrulae WSM1271. This strain has been designated as WSM2073 ${ }^{\mathrm{T}}$ (= LMG 24608 = HAMBI 3006) and is now the recognized type strain for the species Mesorhizobium australicum [7]. The species name au.stra.li'cum. N.L. neut. adj. australicum is in reference to where this isolate originated from [7] and represents a dominant chromosomal type strain surviving as a soil saprophyte in the Western Australian wheat belt $[6,8]$ that appears to have the capacity to acquire symbiotic genes through horizontal transfer [9].

In this report we present a summary classification and a set of general features for $M$. australicum strain WSM2073 ${ }^{\mathrm{T}}$ together with the description of the complete genome sequence and its annotation. Here we reveal that a 455.7 $\mathrm{Kb}$ genomic island from the inoculant Mesorhizobium ciceri bv. biserrulae WSM1271 has been horizontally transferred into $M$. australicum strain WSM2073 ${ }^{\mathrm{T}}$ and integrated into the phenylalanine-tRNA gene.

\section{Classification and features}

M. australicum strain WSM2073 ${ }^{\mathrm{T}}$ is a motile, gram negative, non-spore-forming rod (Figure 1 Left and Center) in the order Rhizobiales of the class Alphaproteobacteria. They are moderately fast growing, forming 2-4 mm diameter colonies within 3-4 days and have a mean generation time of $4-6 \mathrm{~h}$ when grown in half Lupin Agar ( $1 / 2 \mathrm{LA})$ broth [10] at $28{ }^{\circ} \mathrm{C}$. Colonies on $1 / 2 \mathrm{LA}$ are whiteopaque, slightly domed, moderately mucoid with smooth margins (Figure 1 Right). Strains of this organism are able to tolerate a $\mathrm{pH}$ range between 5.5 and 9.0. More information on the carbon source utilization and fatty acid profiles were described before [7]. Minimum Information about a Genome Sequence (MIGS) is given in Table 1.

Figure 2 shows the phylogenetic neighborhood of M. australicum strain WSM2073 ${ }^{\mathrm{T}}$ in a $16 \mathrm{~S}$ rRNA sequence based tree. This strain clustered in a tight group which included $M$. shangrilense, $M$. loti and $M$. ciceri and had $>99 \%$ sequence similarity with all four type strains. However, based on a polyphasic taxonomic study we have identified this strain to belong to a new species [7].

\section{Symbiotaxonomy}

M. australicum strain WSM2073 ${ }^{\mathrm{T}}$ has an extremely narrow legume host range for symbiosis only forming partially effective nitrogen-fixing root nodules on Biserrula pelecinus $L$ [6]. This strain also nodulates the closely related species Astragalus membranaceus but does not nodulate 21 other legume species nodulated by Mesorhizobium spp. [6]. Strain WSM2073т has similar highly specific symbiotic nodulation capabilities to M. ciceri bv. biserrulae WSM1271, but is a poor $\mathrm{N}$-fixer on B. pelecinus $\mathrm{L}$.
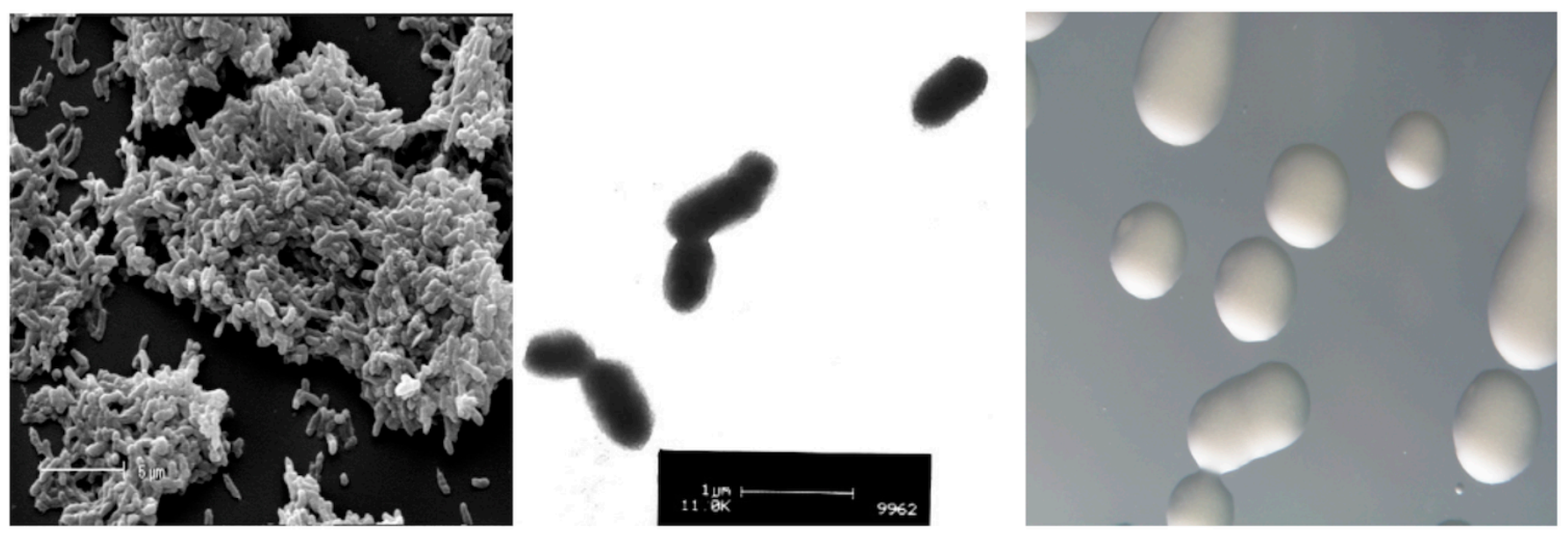

Figure 1. Images of M. australicum strain WSM2073' using scanning (Left) and transmission (Center) electron microscopy and the appearance of colony morphology on a solid medium (Right). 
Table 1. Classification and general features of $M$. australicum strain WSM $2073^{\top}$ according to the MIGS recommendations [11].

\begin{tabular}{|c|c|c|c|}
\hline MIGS ID & Property & Term & Evidence code \\
\hline & \multirow{7}{*}{ Current classification } & Domain Bacteria & TAS [12] \\
\hline & & Phylum Proteobacteria & TAS [13] \\
\hline & & Class Alphaproteobacteria & TAS $[14,15]$ \\
\hline & & Order Rhizobiales & TAS $[15,16]$ \\
\hline & & Family Phyllobacteriaceae & TAS $[15,17]$ \\
\hline & & Genus Mesorhizobium & TAS [18] \\
\hline & & Species Mesorhizobium australicum & TAS [7] \\
\hline & Gram stain & Negative & TAS [7] \\
\hline & Cell shape & Rod & TAS [7] \\
\hline & Motility & Motile & TAS [7] \\
\hline & Sporulation & Non-sporulating & TAS [19] \\
\hline & Temperature range & Mesophile & TAS [19] \\
\hline & Optimum temperature & $28^{\circ} \mathrm{C}$ & TAS [7] \\
\hline & Salinity & Unknown & NAS \\
\hline \multirow[t]{3}{*}{ MIGS-22 } & Oxyg en requirement & Aerobic & TAS [19] \\
\hline & Carbon source & Arabinose, gentibiose, glucose, mannitol \& melibiose & TAS [7] \\
\hline & Energy source & Chemoorg a notroph & TAS [19] \\
\hline MIGS-6 & Habitat & Soil, root nodule, host & TAS [7] \\
\hline MIGS-15 & Biotic relationship & Free living, Symbiotic & TAS [7] \\
\hline \multirow[t]{3}{*}{ MIGS-14 } & Pathog enicity & None & NAS [19] \\
\hline & Biosafety level & 1 & TAS [20] \\
\hline & Isolation & Root nodule of Biserrula pelecinus. $L$ & TAS [7] \\
\hline MIGS-4 & Geographic location & Northam, Western Australia & TAS [6] \\
\hline MIGS-5 & Nodule collection date & Aug ust 2000 & TAS [6] \\
\hline MIGS-4.1 & Long itude & 116.947875 & TAS [6] \\
\hline MIGS-4.2 & Latitude & -31.530408 & TAS [6] \\
\hline MIGS-4.3 & Depth & $10 \mathrm{~cm}$ & IDA \\
\hline MIGS-4.4 & Altitude & $160 \mathrm{~m}$ & IDA \\
\hline
\end{tabular}

Evidence codes - TAS: Traceable Author Statement (i.e., a direct report exists in the literature); NAS: Non-traceable Author Statement (i.e., not directly observed for the living, isolated sample, but based on a generally accepted property for the species, or anecdotal evidence). These evidence codes are from the Gene Ontology project [21]. If the evidence code is IDA, then the property was directly observed by one of the authors or an expert mentioned in the acknowledgements. 


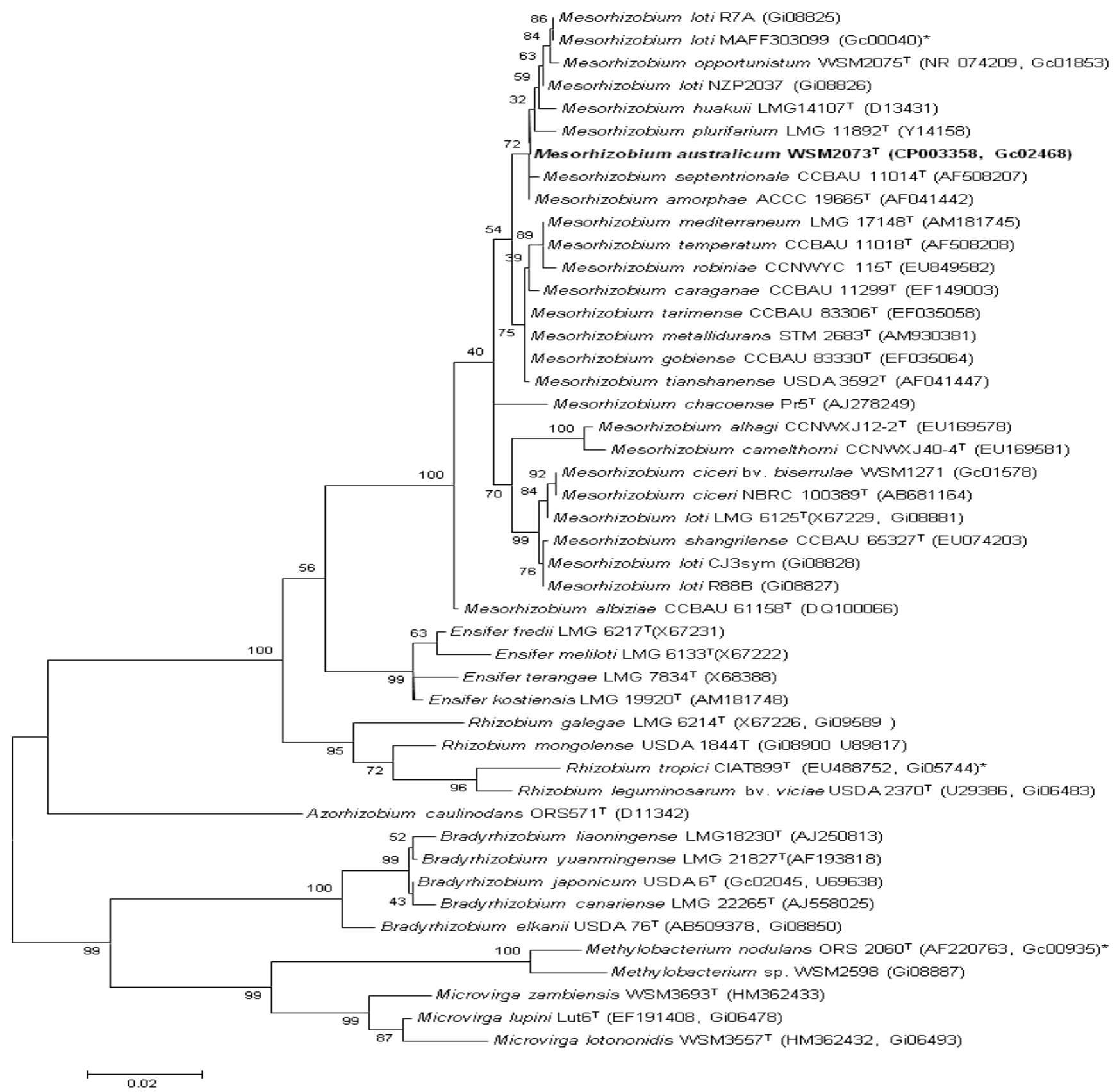

Figure 2. Phylogenetic tree showing the relationships of $M$. australicum strain WSM $2073^{\top}$ with some of the root nodule bacteria in the order Rhizobiales based on aligned sequences of the 16S rRNA gene $(1,290 \mathrm{bp}$ internal region). All sites were informative and there were no gap-containing sites. Phylogenetic analyses were performed using MEGA [22]. The tree was built using the Maximum-Likelihood method with the General Time Reversible model. Bootstrap analysis [23] was performed to assess the support of the clusters. Type strains are indicated with a superscript T. Brackets after the strain name contain a DNA database accession number and/or a GOLD ID (beg inning with the prefix G) for a sequencing project registered in GOLD [24] Published genomes are indicated with an asterisk. 


\begin{tabular}{lll}
\hline \multicolumn{2}{l}{ Table 2. Genome sequencing project information for Mesorhizobium australic um strain WSM2073 } \\
\hline MIGS ID & Property & Term \\
\hline MIGS-31 & Finishing quality & Finished \\
MIGS-28 & Libraries used & Illumina GAii shotgun library, 454 Titanium standard library and paired end 454 \\
& & libraries \\
MIGS-29 & Sequencing platforms & Illumina and 454 technologies \\
MIGS-31.2 & Sequencing coverage & 454 standard and paired end (28x) and Illumina (2159x); total 2187x \\
MIGS-30 & Assemblers & Newbler v 2.3 and Velvet v 0.7.63, PHRAP SPS-4.24 and CONSED \\
MIGS-32 & Gene calling method & Prodigal v.2.50, GenePrimp \\
& Genbank ID & CP003358 \\
& Genbank Date of Release & December 28, 2012 \\
& GOLD ID & Gc02468 \\
& NCBI project ID & 47287 \\
& Database: IMG & 2509276022 \\
& Project relevance & Symbiotic nitrogen fixation, agriculture \\
\hline
\end{tabular}

\section{Genome sequencing and annotation} Genome project history

This organism was selected for sequencing on the basis of its environmental and agricultural relevance to issues in global carbon cycling, alternative energy production, and biogeochemical importance, and is part of the Community Sequencing Program at the US Department of Energy Joint Genome Institute (JGI) for projects of relevance to agency missions. The genome project is deposited in the Genomes OnLine Database [24] and the complete genome sequence in GenBank. Sequencing, finishing and annotation were performed by the DOE Joint Genome Institute (JGI). A summary of the project information is shown in Table 2.

\section{Growth conditions and DNA isolation}

M. australicum strain WSM2073 ${ }^{\mathrm{T}}$ was grown to mid logarithmic phase in TY medium (a rich medium) [25] on a gyratory shaker at $28^{\circ} \mathrm{C}$. DNA was isolated from $60 \mathrm{~mL}$ of cells using a CTAB (Cetyl trimethylammonium bromide) bacterial genomic DNA isolation method.

\section{Genome sequencing and assembly}

The draft genome of $M$. australicum strain WSM $2073^{\mathrm{T}}$ was generated at the DOE Joint genome Institute (JGI) using a combination of Illumina [26] and 454 technologies [27]. For this, genome we constructed and sequenced an Illumina GAii shotgun library which generated 10,509,788 reads totaling $378.4 \mathrm{Mb}$, a 454 Titanium standard library which generated 235,807 reads and paired end 454 libraries with an average insert sizes of $26.3 \mathrm{~Kb}$ $/ 10.9 \mathrm{~Kb}$ which generated 221,877/139,171 reads totaling $257.0 \mathrm{Mb}$ of 454 data. All general aspects of library construction and sequencing performed in this project can be found at the DOE Joint Genome Institute website. The initial draft assembly contained 14 contigs in 1 scaffold. The 454 Titanium standard data and the 454 paired end data were assembled together with Newbler, version 2.3. The Newbler consensus sequences were computationally shredded into $2 \mathrm{~Kb}$ overlapping fake reads (shreds). Illumina sequencing data was assembled with VELVET, version 0.7.63 [28], and the consensus sequences were computationally shredded into $1.5 \mathrm{~Kb}$ overlapping fake reads (shreds). We integrated the 454 Newbler consensus shreds, the Illumina VELVET consensus shreds and the read pairs in the 454 paired end library using parallel phrap, version SPS - 4.24 (High Performance Software, LLC). The software Consed [29-31] was used in the following finishing process. Illumina data was used to correct potential base errors and increase consensus quality using the software Polisher developed at JGI (Alla Lapidus, unpublished). Possible mis-assemblies were corrected using gapResolution (Cliff Han, unpublished), Dupfinisher [32], or sequencing cloned bridging PCR fragments with subcloning. Gaps between contigs were closed by editing in Consed, by PCR and by Bubble PCR (JF Cheng, unpublished) primer walks. A total of 59 additional reactions were necessary to close gaps and to raise the quality of the finished sequence. The total size of the genome is 6,200,534 bp and the final assembly is based on $257 \mathrm{Mb}$ of $454 \mathrm{draft}$ data which provides an average $28 \times$ coverage of the genome and $13,385 \mathrm{Mb}$ of Illumina draft data which provides an average $2159 \times$ coverage of the genome. 


\section{Genome annotation}

Genes were identified using Prodigal [33] as part of the Oak Ridge National Laboratory genome annotation pipeline, followed by a round of manual curation using the JGI GenePrimp pipeline [34]. The predicted CDSs were translated and used to search the National Center for Biotechnology Information (NCBI) non-redundant database, UniProt, TIGRFam, Pfam, PRIAM, KEGG, COG, and InterPro databases. These data sources were combined to assert a product description for each predicted protein. Non-coding genes and miscellaneous features were predicted using tRNAscanSE [35], RNAMMer [36], Rfam [37], TMHMM [38], and SignalP [39]. Additional gene prediction analyses and functional annotation were performed within the Integrated Microbial Genomes (IMGER) platform [40].

\section{Genome properties}

The genome is $6,200,534 \mathrm{bp}$ long with a $62.84 \%$ GC content (Table 3, Figure 3 ) and comprised of a single chromosome. From all the genes present in the genome, 6,013 were protein coding genes and 67 RNA only encoding genes. Two hundred and twenty one pseudogenes were also identified. The majority of protein coding genes $(4,875 ; 80.18 \%)$ were assigned a putative function whilst the remaining protein coding genes were annotated as encoding hypothetical proteins. The distribution of genes into COGs functional categories is presented in Table 4.

Table 3. Genome Statistics for Mesorhizobium australicum strain WSM2073'.

\begin{tabular}{|c|c|c|}
\hline Attribute & Value & $\%$ of Total \\
\hline Genome size (bp) & $6,200,534$ & 100 \\
\hline DNA coding region (bp) & $5,371,783$ & 86.63 \\
\hline DNA G+C content (bp) & $3,896,642$ & 62.84 \\
\hline Number of replicons & 1 & 100 \\
\hline Extrachromosomal elements & 0 & \\
\hline Total genes & 6,080 & 100 \\
\hline RNA genes & 67 & 1.1 \\
\hline Protein-coding genes & 6,013 & 98.9 \\
\hline Genes with function prediction & 4,875 & 80.18 \\
\hline Genes assig ned to COGs & 4,877 & 80.21 \\
\hline Genes assigned Pfam domains & 5,082 & 83.40 \\
\hline Genes with signal peptides & 536 & 8.82 \\
\hline Genes with transmembrane helices & 1,434 & 23.59 \\
\hline
\end{tabular}




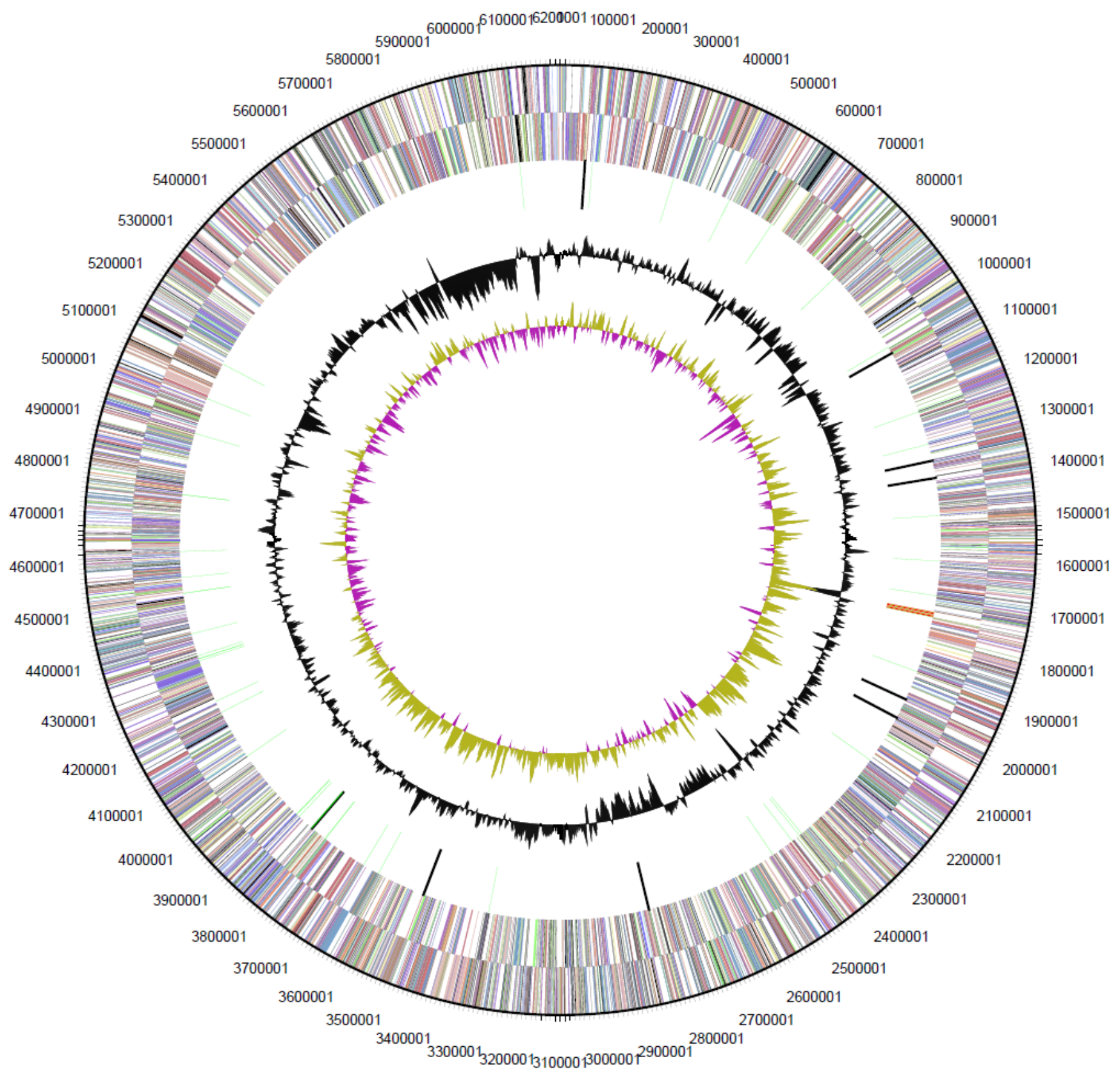

Figure 3. Graphical circular map of the chromosome of Mesorhizobium australicum WSM2073'. From outside to the center: Genes on forward strand (color by COG categ ories as denoted by the IMG platform), Genes on reverse strand (color by COG categ ories), RNA genes (tRNAs green, sRNAs red, other RNAs black), GC content, GC skew. 
Table 4. Number of protein coding genes of Mesorhizobium australicum WSM2073 associated with the general COG functional categories.

\begin{tabular}{crrl}
\hline Code & Value & \%age & Description \\
\hline J & 192 & 3.56 & Translation, ribosomal structure and biogenesis \\
A & 1 & 0.02 & RNA processing and modification \\
K & 450 & 8.34 & Transcription \\
L & 179 & 3.32 & Replication, recombination and repair \\
B & 5 & 0.09 & Chromatin structure and dynamics \\
D & 35 & 0.65 & Cell cycle control, mitosis and meiosis \\
Y & 0 & 0.00 & Nuclear structure \\
V & 60 & 1.11 & Defense mechanisms \\
T & 214 & 3.96 & Signal transduction mechanisms \\
M & 305 & 5.65 & Cell wall/membrane biog enesis \\
N & 42 & 0.78 & Cell motility \\
Z & 0 & 0.00 & Cytoskeleton \\
W & 1 & 0.02 & Extracellular structures \\
U & 115 & 2.13 & Intracellular trafficking and secretion \\
O & 180 & 3.33 & Posttranslational modification, protein turnover, chaperones \\
C & 302 & 5.59 & Energy production conversion \\
G & 511 & 9.47 & Carbohydrate transport and metabolism \\
E & 634 & 11.75 & Amino acid transport metabolism \\
F & 94 & 1.74 & Nucleotide transport and metabolism \\
H & 201 & 3.72 & Coenzyme transport and metabolism \\
I & 216 & 4.00 & Lipid transport and metabolism \\
P & 239 & 4.43 & Inorganic ion transport and metabolism \\
Q & 156 & 2.89 & Secondary metabolite biosynthesis, transport and catabolism \\
R & 699 & 12.95 & General function prediction only \\
S & 567 & 10.50 & Function unknown \\
\hline & 1203 & 19.79 & Not in COGS \\
\hline & & & \\
\hline
\end{tabular}

\section{Acknowledgements}

This work was perform ed under the auspices of the US Department of Energy's Office of Science, Biological and Environmental Research Program, and by the University of California, Lawrence Berkeley National Laboratory under contract No. DE-AC02-05CH11231, Lawrence Livermore National Laboratory under Contract No. DEAC52-07NA27344, and Los Alamos National Laboratory under contract No. DE-AC02-06NA25396. We gratefully acknowledge the funding received from Aus tralian
Research Council Discovery grant (DP0880896), Murdoch University Strategic Research Fund through the Crop and Plant Research Institute (CaPRI) and the Centre for Rhizobium Studies (CRS) at Murdoch University. The authors would like to thank the Australia-China Joint Research Centre for Wheat Improvem ent (ACCWI) and SuperSeed Technologies (SST) for financially supporting Mohamed Ninawi's PhD project. 


\section{References}

1. O'Hara GW. The role of nitrog en fixation in crop production. J Crop Prod 1998; (1):115-138. http://dx.doi.org/10.1300//144v01n02 06

2. Gregorich EG, Rochette P, VandenBygaart AJ, Angers DA. Greenhouse gas contributions of ag ricultural soils and potential mitigation practices in Eastern Canada. Soil Tillage Res 2005; 83:53-72. http://dx.doi.org/10.1016/j.still.2005.02.009

3. Howieson JG, O'Hara GW, Carr SJ. Changing roles for leg umes in Mediterranean ag riculture: developments from an Australian perspective. Field Crops Res 2000; 65:107-122. http://dx.doi.org/10.1016/S0378-4290(99)00081-7

4. Loi A, Howieson JG, Nutt BJ, Carr SJ. A second generation of annual pasture leg umes and their potential for inclusion in Mediterranean-type farming systems. Aust J Exp Agric 2005; 45:2 89-299. http://dx.doi.org/10.1071/EA03134

5. Howieson JG, Loi A, Carr SJ. Biserrula pelecinus L. - a leg ume pasture species with potential for acid, duplex soils which is nodulated by unique rootnodule bacteria. Aust J Agric Res 1995; 46:9971009. http://dx.doi.org/10.1071/AR9950997

6. Nandasena KG, O'Hara GW, Tiwari RP, Sezmis E, Howieson JG. In situ lateral transfer of symbiosis islands results in rapid evolution of diverse competitive strains of mesorhizobia suboptimal in symbiotic nitrog en fixation on the pasture leg ume Biserrula pelecinus L. Environ Microbiol 2007; 9:2496-2511. PubMed http://dx.doi.org/10.1111/j.1462$\underline{2920.2007 .01368 . x}$

7. Nandasena KG, O'Hara GW, Tiwari RP, Willems A, Howieson JG. Mesorhizobium australicum sp. nov. and Mesorhizobium opportunistum sp. nov., isolated from Biserrula pelecinus L. in Australia. Int J Syst Evol Microbiol 2009; 59:2140-2147. PubMed http://dx.doi.org/10.1099/ijs.0.005728-0

8. Nandasena KG, O'Hara GW, Tiwari RP, Willlems A, Howieson JG. Mesorhizobium ciceri biovar biserrulae, a novel biovar nodulating the pasture leg ume Biserrula pelecinus L. Int I Syst Evol Microbiol 2007; 57:1041-1045. PubMed http://dx.doi.org/10.1099/ijs.0.64891-0

9. Nandasena KG, O'Hara GW, Tiwari RP, Howieson JG. Rapid in situ evolution of nodulating strains for $B$ iserrula pelecinus $L$. through lateral transfer of a symbiosis island from the original mesorhizobial inoculant. Appl Environ Microbiol 2006; 72:73657367. PubMed http://dx.doi.org/10.1128/AEM.00889-06
10. Howieson JG, Ewing MA, D'antuono MF. Selection for acid tolerance in Rhizobium meliloti. Plant Soil 1988; 105:179-188. http://dx.doi.org/10.1007/BF02376781

11. Field D, Garrity G, Gray T, Morrison N, Seleng ut J, Sterk P, Tatusova T, Thomson N, Allen M, Angiuoli $\mathrm{SV}$, et al. Towards a richer description of our complete collection of genomes and metagenomes "Minimum Information about a Genome Sequence " (MIGS) specification. Nat Biotechnol 2008; 26:541-547. PubMed http://dx.doi.org/10.1038/nbt1360

12. Woese CR, Kandler O, Wheelis ML. Towards a natural system of organisms: proposal for the domains Archaea, Bacteria, and Eucarya. Proc Natl Acad Sci USA 1990; 87:4576-4579. PubMed http://dx.doi.org/10.1073/pnas.87.12.4576

13. Garrity GM, Bell JA, Lilburn T. Phylum XIV. Proteobacteria phyl. nov. In: Garrity GM, Brenner DJ, Krieg NR, Staley JT (eds), Bergey's Manual of Systematic Bacteriology, Second Edition, Volume 2, Part B, Springer, New York, 2005, p. 1.

14. Garrity GM, Bell JA, Lilburn T. Class I. Alphap roteobacteria class. In: Garrity GM, Brenner DJ, Kreig NR, Staley JT, editors. Bergy's Manual of Systematic Bacteriology. Second ed: New York: Springer - Verlag; 2005.

15. Validation List No. 107. List of new names and new combinations previously effectively, but not validly, published. Int I Syst Evol Microbiol 2006; 56:1-6. PubMed http://dx.doi.org/10.1099/ijs.0.64188-0

16. Kuykendall LD. Order VI. Rhizobiales ord. nov. In: Garrity GM, Brenner DJ, Kreig NR, Staley JT, editors. Bergy's Manual of Systematic Bacteriology. Second ed: New York: Springer - Verlag; 2005. p 324.

17. Mergaert J, Swing s J. Family IV. Phyllobacteriaceae In: Garrity GM, Brenner DJ, Kreig NR, Staley JT, editors. Bergy's Manual of Systematic Bacteriology. Second ed: New York: Springer - Verlag; 2005. p 393.

18. Jarvis BDW, Van Berkum $P$, Chen WX, Nour SM, Fernandez MP, Cleyet-Marel JC, Gillis M. Transfer of Rhizobium loti, Rhizobium huakuii, Rhizobium ciceri, Rhizobium mediterraneum, Rhizobium tianshanense to Mesorhizobium gen.nov. Int J Syst Evol Microbiol 1997; 47:895-898. http://dx.doi.org/10.1099/00207713-47-3-895 
19. Chen WX, Wang ET, Kuykendall LD. The Proteobacteria. New York: Springer - Verlag; 2005.

20. PRO-131W1 P. Saccharomyces cerevisiae Unibroue Blanche de Chambly. PREMIUM ALE(Isolated from sample of Unibroue Blanche de Chambly on tap in Downtown Disney .).

21. Ashburner M, Ball CA, Blake JA, Botstein D, Butler $\mathrm{H}$, Cherry JM, Davis AP, Dolinski K, Dwight SS, Eppig JT, et al. Gene ontology: tool for the unification of biology. The Gene Ontology Consortium. Nat Genet 2000; 25:25-29. PubMed http://dx.doi.org/10.1038/75556

22. Kumar S, Tamura K, Nei M. MEGA3: Integrated software for Molecular Evolutionary Genetics Analysis and sequence alig nment. Brief Bioinform 2004; 5:150-163. PubMed http://dx.doi.org/10.1093/bib/5.2.150

23. Felsenstein J. Confidence limits on phylogenies: an approach using the bootstrap. Evolution 1985; 39:783-791. http://dx.doi.org/10.2307/2408678

24. Liolios K, Mavromatis K, Tavernarakis N, Kyrpides NC. The Genomes On Line Database (GOLD) in 2007: status of genomic and metagenomic projects and their associated metadata. Nucleic Acids Res 2008; 36:D475-D479. PubMed http://dx.doi.org/10.1093/nar/g km884

25. Reeve WG, Tiwari RP, Worsley PS, Dilworth MJ, Glenn AR, Howieson JG. Constructs for insertional mutagenesis, transcriptional signal localization and gene regulation studies in root nodule and other bacteria. Microbiology 1999; 145:1307-1316.

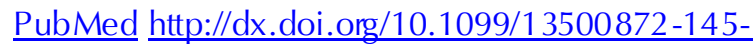
$\underline{6-1307}$

26. Bennett S. Solexa Ltd. Pharmacogenomics 2004; 5:433-438. PubMed http://dx.doi.org/10.1517/14622416.5.4.433

27. Margulies M, Egholm M, Altman WE, Attiya S, Bader JS, Bemben LA, Berka J, Braverman MS, Chen YJ, Chen Z, et al. Genome sequencing in microfabricated high-density picolitre reactors. Nature 2005; 437:376-380. PubMed

28. Zerbino DR. Using the Velvet de novo assembler for short-read sequencing technolog ies. Current Protocols in Bioinformatics 2010; Chapter 11:Unit 115.

29. Ewing B, Green P. Base-calling of automated sequencer traces using phred. II. Error probabilities. Genome Res 1998; 8:186-194. PubMed http://dx.doi.org/10.1101/gr.8.3.175

30. Ewing B, Hillier L, Wendl MC, Green P. Basecalling of automated sequencer traces using phred.
I. Accuracy assessment. Genome Res 1998; 8:175185. PubMed http://dx.doi.org/10.1101/gr.8.3.175

31. Gordon D, Abajian C, Green P. Consed: a graphical tool for sequence finishing. Genome Res 1998; 8:195-202. PubMed http://dx.doi.org/10.1101/gr.8.3.195

32. Han C, Chain P. Finishing repeat regions automatically with Dupfinisher. In: Valafar HRAH, editor. Proceeding of the 2006 international conference on bioinformatics \& computational biology: CSREA Press; 2006. p 141-146.

33. Hyatt D, Chen GL, Locascio PF, Land ML, Larimer FW, Hauser LJ. Prodigal: prokaryotic gene recog nition and translation initiation site identification.

BMC Bioinformatics 2010; 11:119. PubMed http://dx.doi.org/10.1186/1471-2105-11-119

34. Pati A, Ivanova NN, Mikhailova N, Ovchinnikova G, Hooper SD, Lykidis A, Kyrpides NC.

GenePRIMP: a gene prediction improvement pipeline for prokaryotic genomes. Nat Methods 2010;

7:455-457. PubMed http://dx.doi.org/10.1038/nmeth.1457

35. Lowe TM, Eddy SR. tRNAscan-SE: a prog ram for improved detection of transfer RNA genes in genomic sequence. Nucleic Acids Res 1997; 25:955964. PubMed

36. Lagesen K, Hallin P, Rodland EA, Staerfeldt HH, Rognes T, Ussery DW. RNAmmer: consistent and rapid annotation of ribosomal RNA genes. Nucleic Acids Res 2007; 35:3100-3108. PubMed http://dx.doi.org/10.1093/nar/g km160

37. Griffiths-Jones S, Bateman A, Marshall M, Khanna A, Eddy SR. Rfam: an RNA family database. Nucleic Acids Res 2003; 31:439-441. PubMed http://dx.doi.org/10.1093/nar/g kg 006

38. Krogh A, Larsson B, von Heijne G, Sonnhammer EL. Predicting transmembrane protein topology with a hidden Markov model: application to complete genomes. J Mol Biol 2001; 305:567-580. PubMed http://dx.doi.org/10.1006/jmbi.2000.4315

39. Bendtsen JD, Nielsen H, von Heijne G, Brunak S. Improved prediction of sig nal peptides: Sig nalP 3.0. J Mol Biol 2004; 340:783-795. PubMed http://dx.doi.org/10.1016/j.jmb.2004.05.028

40. Markowitz VM, Mavromatis K, Ivanova NN, Chen IM, Chu K, Kyrpides NC. IMG ER: a system for microbial genome annotation expert review and curation. Bioinformatics 2009; 25:2271-2278.

$\underline{\text { PubMed }}$

http://dx.doi.org/10.1093/bioinformatics/btp393 